Original article

\title{
Primary open-angle glaucoma combined with concomitant somatic pathology
}

\author{
Aigul Sh. Zagidullina, Bulat M. Aznabaev \\ Bashkir State Medical University, Ufa, Russia
}

Received 28 June 2020, Revised 1 March 2021, Accepted 26 April 2021

(C) 2020, Russian Open Medical Journal

\begin{abstract}
The goal of the study was to assess the role of concomitant somatic pathology and calculate the total comorbidity index of primary open-angle glaucoma (POAG) in different age groups.

Material and Methods - The study included 624 patients (1199 eyes) with POAG aged 45 to 93 years. The control group included 161 people without glaucoma. Patients underwent a comprehensive ophthalmological examination. The Charlson comorbidity index (Cl) was calculated, taking into account the concomitant somatic diseases and the age of the patients. Statistical processing of the obtained material was carried out using the IBM SPSS Statistics v. 21 program with standard methods of descriptive statistics.

Results - with an increase in the age of POAG patients, significant growth in the number of patients with hypertension, coronary heart disease, cerebrovascular accident, atherosclerosis, degenerative diseases of the nervous system, diabetes mellitus, respiratory diseases, musculoskeletal system, and other pathologies were observed. $\mathrm{Cl}$ was increased in POAG patients with age: 3.02 times for the old age patients, 4.2 times for very old age subjects, compared with middle-aged patients $(p<0.001)$, as well as 1.42 and 1.97 times, respectively, compared with the control group $(p<0.001)$.

Conclusion - In patients with POAG, the number of patients with hypertension, ischemic heart disease, cerebrovascular disorders, atherosclerosis, degenerative diseases of the nervous system, diabetes mellitus, respiratory diseases, musculoskeletal system disorders, and other pathologies increased significantly with age. The comorbidity index in POAG patients exhibited growth with age: 3.02 times in the old age group and 4.2 times in the group of very old age people vs. the group of middle-aged patients $(p<0.001) ;$ and 1.42 and 1.97 times, respectively, vs. the control group $(p<0.001)$.
\end{abstract}

Keywords: primary open-angle glaucoma, concomitant somatic pathology, Charlson comorbidity index, age groups.

Cite as Zagidullina AZh, Aznabaev BM. Primary open-angle glaucoma combined with concomitant somatic pathology. Russian Open Medical Journal 2021; 10: e0417.

Correspondence to Aigul Sh. Zagidullina. Address: Bashkir State Medical University, 3, Lenin Street, 450008, Ufa, Russia. Phone: +7(347)2829179. +79173472449. Email: aigul.zagidullina@gmail.com.

\section{Introduction}

Currently, there is evidence that systemic factors play a specific role in the pathogenesis of primary open-angle glaucoma (POAG), exacerbating its course [1].

The main concomitant systemic diseases, primarily affecting POAG, include the pathology of the cardiovascular system: arterial hypertension, ischemic heart disease, discirculatory encephalopathy, as well as pathology of the endocrine system [24].

Epidemiological data indicate conflicting results of systemic hypertension's role in glaucoma development and progression [2]. Studies show that an increased prevalence of glaucoma is observed in patients with both extremes of the blood pressure range and differs in various age groups [5]

The issue of the correlation between POAG and atherosclerosis is debatable [6]. POAG and ischemic heart disease with atherosclerotic lesions of the coronary vessels from the point of view of hemodynamics may have common pathogenesis links. Several studies have revealed a significantly higher overall incidence of ischemic heart disease in the POAG group compared with the group of people without glaucoma $[7,8]$. A connection between the severity of POAG and decreased blood flow in the brain and eye vessels was found in patients with signs of cerebral insufficiency [9]. Along with this, it is believed that vascular dysregulation rather than a chronic decrease in blood flow due to atherosclerosis can lead to local vasospasm and systemic hypotension and, as a consequence, cause low perfusion pressure and insufficient blood supply to the optic nerve head [10].

The recent publications do not exhibit a clear correlation between POAG and concomitant endocrine pathology, primarily diabetes mellitus, and hypothyroidism, among patients of different age groups $[3,11]$.

There is evidence, though, that the presence of long-term hyperglycemia in diabetes, along with lipid metabolism disorders, may increase the risk of damage to retinal neurons as a result of metabolic stress, as well as impaired autoregulation $[12,13]$.

Thus, the concept of the correlation between concomitant somatic pathology and POAG can serve as a subject for further research. It is essential to study the relationship between the common POAG pathogenesis and many general somatic diseases. 
It is also of interest to assess a total load of somatic pathology in POAG patients of different age groups.

Among the existing systems for assessing comorbidity in the scientific literature, the most common is the Charlson index proposed in 1987 by Professor M.E. Charlson [14]. This comorbidity index is a scoring system for assessing age and specific comorbidities. The total score includes points corresponding to comorbid diseases, and points are added for every ten years of life if the patient exceeds the age of forty.

The goal of our study was to assess the role of concomitant somatic pathology and calculate the total comorbidity index in POAG patients of different age groups.

\section{Material and Methods}

\section{Study design}

The study included 624 patients (1199 eyes) with POAG of various stages, aged 45 to 93 (average 64.59) years. The control group included 161 people (322 eyes) without glaucoma, comparable to patients with POAG by gender and age. The participants of the study submitted their written consent.

Each patient was considered as a separate clinical case while taking into account the data of the worst affected eye in the asymmetric course of the glaucomatous process.

All subjects were divided into three groups according to the current WHO age classification: the first with 215 (34.46\%) middleaged patients (45-59 years old), the second with 275 (44.07\%) old aged patients (60-74), the third included $134(21.47 \%)$ very old patients ( 75 years old and up).

All patients underwent a comprehensive ophthalmological examination, as well as had their medical documentation analyzed (outpatient records, medical history, etc.) to verify the somatic comorbidity.

\section{Inclusion criteria}

- Primary open-angle glaucoma diagnosis (H40.1) established based on clinical, laboratory, and instrumental research methods by modern diagnostic criteria [1];

- age over 45;

- availability of physical examination results.

The participants of the study submitted their written informed consent.

\section{Exclusion criteria}

- refractive errors (astigmatism above 2.0D, moderate and high myopia and hyperopia);

- pronounced opacity of the ocular media, pathology of the optic nerve and retina of non-glaucoma genesis;

- acute inflammatory and degenerative diseases of the organ of vision.

- acute infectious pathology, chronic diseases of internal organs in the acute stage.

\section{Study environment}

The study was carried out at the Department of Ophthalmology with the Institute of Continuing Professional
Education course, Bashkir State Medical University, the Ministry of Healthcare of Russia, and the Laser Vision Center Optimed, Ufa.

The sample size was not pre-calculated. The Shapiro -Wilk test showed that the total sample of patients with POAG used in the study was distributed according to the normal distribution law.

\section{Basic features of patients}

Among all patients with POAG, 333 were men, 444 were women. Of these, $448(71.79 \%)$ were women, and $176(28.21 \%)$ were men. Stage I glaucoma was diagnosed in 397 (31.81\%) eyes, stage II in 624 (50\%), III in 128 (10.26\%), IV in 50 (4.01\%).

Anamnestic and documentary evidence was collected to assess the somatic status, including the conclusion of a therapist and neurologist in the relevant medical documentation. We took into account the presence of the cardiovascular diseases: arterial hypertension (AH) (ICD-10 I11 code), ischemic heart disease (IHD) (ICD-10 I20 - I25 code), chronic cerebrovascular insufficiency (ICD10165 - 168 code), atherosclerosis (ATS) (ICD-10 170.9 code), arterial hypotension (ICD-10 195.9 code); autonomic nervous system dysfunction (ICD-10 G90 code); degenerative diseases of the nervous system (ICD-10 G30-32 code), incl. Alzheimer's disease (ICD-10 G30 code), Parkinson's disease (ICD-10 G20 code); diabetes mellitus (DM) type I and II (ICD-10 E10-14 code); thyroid disorders (ICD-10 E00-07 code); chronic respiratory diseases (ICD10 J00-J99 code), including bronchial asthma (ICD-10 J45 code), chronic non-specific lung diseases (ICD-10 J40-47 code), chronic bronchitis (ICD-10 J42 code); gastrointestinal tract diseases (ICD-10 K20-K31 code); musculoskeletal system disorders (ICD-10 M20-25, M30-35 code) and other pathologies.

The calculation of Charlson's comorbidity index (Charlson M.E., 1987, modified by Deyo R.A., 1992) was carried out considering concomitant somatic diseases and the age of the patients [14, 15].

\section{Statistical analysis}

Statistical processing of the obtained material was carried out using the IBM SPSS Statistics v. 21 program with standard methods of descriptive statistics calculating the reliability criterion and significance level. The sample size was not pre-calculated.

We used a t-test of means for independent samples in the absence of the assumption of dispersion equality. It was confirmed by Levene's criterion and a comparison of qualitative variables using the nonparametric chi-square criterion. The significance level in testing statistical hypotheses was assumed to be 0.05 .

\section{Results}

A comparative analysis of the concomitant somatic pathology prevalence in patients with POAG of different age groups and control groups is presented in Table 1.

An increase in concomitant somatic pathology was noted in the groups of patients with POAG increasing with age. This trend was most clearly observed among patients with various cardiovascular pathologies, degenerative diseases of the nervous system, and respiratory system disorders. Thus, the share of patients diagnosed with hypertension increased 1.84 times in the age group of 60-74 years and 2.09 times in the group of over 75 years compared with the middle age group of 45-59 years $(p<0.001)$. The share of patients with ischemic heart disease in the old age group and the very old age group exceeded the share of 
middle-aged patients by 2.76 times and 3.97 times, respectively $(p<0.001)$

The share of patients with chronic cerebrovascular diseases in the group of 60-74 years old increased 4.25 times, and 6.77 times in the group over 75 years old compared with the group of 45-59 years old $(p<0.001)$. Respectively, the share of patients diagnosed with atherosclerosis increased 2.82 times in old age and 3.55 times in very old age compared with the middle-aged patients $(p<0.001)$.

Among patients with cardiovascular diseases, the opposite tendency was observed in those who had arterial hypotension: the share of the old age patients and the very old age patients was lower than the share of middle-aged patients by 1.66 times and 3.42 times, respectively $(p<0.05)$.

The share of patients with autonomic nervous system dysfunction in the group of 60-74 years old was 3.65 times lower than in the group of $45-59$ years old $(p<0.05)$. People over 75 years old did not have this diagnosis.

When assessing the prevalence of endocrine system pathology, it was noted that the share of people with diabetes exceeded the share of middle-aged patients in the old age group and very old age group $(p<0.001) 2.18$ times and 2.98 times $(p<0.05)$, accordingly. A downward tendency in thyroid pathology was observed with increasing age: the share of this nosology vs. the middle age group was 1.18 and 1.66 times less common in patients of 60-74 and over 75 years old, respectively.

We saw a significant 7.9 -fold increase $(p<0.05)$ in the share of degenerative diseases of the nervous system in the 60-74 years age group, and 19.48 times increase $(p<0.001)$ in the group of 75 years and older, compared with the age group of $45-59$ years old.

The share of patients with respiratory system diseases in the group of 60-74 years old exhibited 1.62 ( $p<0.05$ ) augmentation and 2.16 growth in the group over 75 years old $(p<0.001)$, compared with the middle age group.

An upward tendency in digestive system diseases was observed in the old age group (1.12 times) and in the group of people over 75 years old (1.28 times), compared with the middle age group.

The share of patients with musculoskeletal system disorders exceeded the share of middle-aged patients among the old age group 3.32 times, as well as in the very old age group, and we observed a 3.51 times increase $(p<0.001)$.

There was no significant difference between the indicators of concomitant somatic pathology of POAG patients in general compared with the control group.

Table 1. Concomitant somatic pathology in the studied groups of patients with POAG depending on their age

\begin{tabular}{|c|c|c|c|c|c|c|c|c|}
\hline \multirow[b]{2}{*}{ Somatic comorbidity } & \multicolumn{5}{|c|}{ Age } & \multirow[b]{2}{*}{$\begin{array}{c}\text { Total POAG } \\
(n=624)\end{array}$} & \multirow{2}{*}{$\begin{array}{l}\text { Control } \\
\text { group } \\
(n=161)\end{array}$} & \multirow{2}{*}{$\begin{array}{c}\text { Chi-square test } \\
\text { P-level } \\
\text { in comparison } \\
\text { with the CG }\end{array}$} \\
\hline & $\begin{array}{l}\text { Middle age } \\
\quad(n=215)\end{array}$ & $\begin{array}{l}\text { Old age } \\
(n=275)\end{array}$ & $\begin{array}{l}\text { Chi-square test } \mathrm{P}- \\
\text { level in comparison } \\
\text { with the MAG }\end{array}$ & $\begin{array}{c}\text { Very old } \\
\text { age } \\
(n=134)\end{array}$ & $\begin{array}{l}\text { Chi-square test P- } \\
\text { level in comparison } \\
\text { with the MAG }\end{array}$ & & & \\
\hline Hypertension, n (\%) & $63(29.3)$ & $148(53.82)$ & $<0.001$ & $82(61.19)$ & $<0.001$ & $293(46.95)$ & $72(44.72)$ & 0.613 \\
\hline Ischemic heart disease, $\mathrm{n}(\%)$ & $19(8.83)$ & $67(24.36)$ & $<0.001$ & $47(35.07)$ & $<0.001$ & $133(21.31)$ & $30(18.63)$ & 0.455 \\
\hline Cerebrovas-cular disorders, $\mathrm{n}(\%)$ & $9(4.19)$ & $49(17.82)$ & $<0.001$ & $38(28.36)$ & $<0.001$ & $96(15.38)$ & $19(11.8)$ & 0.252 \\
\hline Atheroscle-rosis, n (\%) & $28(13.02)$ & $101(36.73)$ & $<0.001$ & $62(46.27)$ & $<0.001$ & $191(30.61)$ & $44(27.33)$ & 0.418 \\
\hline Arterial hypotension, n (\%) & $22(10.23)$ & $17(6.18)$ & 0.101 & $4(2.99)$ & 0.013 & $43(6.89)$ & $8(4.99)$ & 0.378 \\
\hline Autonomic nervous system disorders, $\mathrm{n}(\%)$ & $20(9.3)$ & $7(2.55)$ & 0.002 & - & - & $27(4.33)$ & $3(1.86)$ & 0.147 \\
\hline Diabetes mellitus, $\mathrm{n}(\%)$ & $15(7.0)$ & $42(15.27)$ & 0.005 & $28(20.89)$ & $<0.001$ & $85(13.62)$ & $20(12.42)$ & 0.691 \\
\hline Thyroid disorders, n (\%) & $24(11.16)$ & $26(9.45)$ & 0.536 & $9(6,72)$ & 0.168 & $59(9.46)$ & $12(7.45)$ & 0.430 \\
\hline Degenerative diseases of the nervous system, $\mathrm{n}(\%)$ & $1(0.46)$ & $10(3.64)$ & 0.019 & $12(8.96)$ & $<0.001$ & $23(3.69)$ & $3(1.86)$ & 0.250 \\
\hline Respiratory diseases, $\mathrm{n}(\%)$ & $25(12.09)$ & $54(19.64)$ & 0.017 & $35(26.12)$ & $<0.001$ & $114(18.26)$ & $27(16.77)$ & 0.659 \\
\hline Digestive diseases, n (\%) & 30 (13.95) & $43(15.64)$ & 0.604 & $24(17.91)$ & 0.321 & $97(15.54)$ & 28 (17.39) & 0.569 \\
\hline Musculoskeletal system disorders, n (\%) & $16(7.44)$ & $68(24.73)$ & $<0.001$ & $35(26.12)$ & $<0.001$ & $119(19.07)$ & 27 (17.39) & 0.504 \\
\hline Other disorders, n (\%) & $14(6.51)$ & $21(7.63)$ & 0.632 & 15 (11.19) & 0.124 & $50(8.01)$ & $16(9.94)$ & 0.433 \\
\hline
\end{tabular}

Qualitative data presented as frequencies and percentages $-n(\%)$. MAG, middle age group; $C G$, control group.

Table 2. Combinations of concomitant somatic pathology in study groups

\begin{tabular}{|c|c|c|c|c|c|c|c|c|}
\hline \multirow[b]{2}{*}{ Somatic comorbidity } & \multicolumn{5}{|c|}{ Age } & \multirow[b]{2}{*}{$\begin{array}{c}\text { Total POAG } \\
(n=624)\end{array}$} & \multirow[b]{2}{*}{$\begin{array}{c}\text { Control group } \\
(n=161)\end{array}$} & \multirow{2}{*}{$\begin{array}{c}\text { Chi-square test } P \text { - } \\
\text { level in } \\
\text { comparison with } \\
\text { the } C G\end{array}$} \\
\hline & $\begin{array}{l}\text { Middle age } \\
\quad(n=215)\end{array}$ & $\begin{array}{l}\text { Old age } \\
(n=275)\end{array}$ & $\begin{array}{l}\text { Chi-square test P- } \\
\text { level in comparison } \\
\text { with the MAG }\end{array}$ & $\begin{array}{l}\text { Very old age } \\
\qquad(n=134)\end{array}$ & $\begin{array}{l}\text { Chi-square test P-level } \\
\text { in comparison with } \\
\text { the MAG }\end{array}$ & & & \\
\hline Comorbidity not diagnosed, n (\%) & $71(33)$ & $42(15.27)$ & $<0.001$ & - & & $113(18.27)$ & $47(29.19)$ & 0.002 \\
\hline 1 comorbidity, $\mathrm{n}(\%)$ & $64(29.76)$ & $59(21.45)$ & 0.036 & $27(20.15)$ & 0.047 & $150(24.04)$ & $37(22.98)$ & 0.779 \\
\hline 2 comorbidities $\mathrm{n}(\%)$ & $51(23.72)$ & $60(21.81)$ & 0.618 & $29(21.64)$ & 0.654 & $140(22.43)$ & 27 (16.77) & 0.118 \\
\hline 3 comorbidities $\mathrm{n}(\%)$ & $19(8.83)$ & $54(19.63)$ & $<0.001$ & $34(25.37)$ & $<0.001$ & $107(17.15)$ & $24(14.9)$ & 0.497 \\
\hline 4 comorbidities $n(\%)$ & $8(3.72)$ & $44(16.0)$ & $<0.001$ & $27(20.15)$ & $<0.001$ & $79(12.66)$ & $16(9.94)$ & 0.346 \\
\hline 5 comorbidities $n(\%)$ & $2(0.93)$ & $16(5.81)$ & $<0.001$ & $15(9.31)$ & $<0.001$ & $33(5.29)$ & $9(5.59)$ & 0.880 \\
\hline 6 and more comorbidities $n(\%)$ & - & - & & $2(1.49)$ & & $2(0.32)$ & $1(0.62)$ & 0.581 \\
\hline Parameter & $\begin{array}{l}\text { Middle age } \\
\quad(n=215)\end{array}$ & $\begin{array}{l}\text { Old age } \\
(n=275)\end{array}$ & $\begin{array}{c}\text { t-criterion P-level } \\
\text { in comparison with } \\
\text { the MAG }\end{array}$ & $\begin{array}{l}\text { Very old age } \\
\qquad(n=134)\end{array}$ & $\begin{array}{c}\text { t-criterion P-level } \\
\text { in comparison with } \\
\text { the MAG }\end{array}$ & $\begin{array}{c}\text { Total POAG } \\
(n=624)\end{array}$ & $\begin{array}{l}\text { Control group } \\
\quad(n=161)\end{array}$ & $\begin{array}{l}\text { t-criterion P-level } \\
\text { in comparison } \\
\text { with the CG }\end{array}$ \\
\hline Comorbidity Index, M $\pm S D$ & $0.97 \pm 0.054$ & $2.93 \pm 0.058$ & $<0.001$ & $4.07 \pm 0.068$ & $<0.001$ & $2.5 \pm 0.060$ & $2.07 \pm 0.096$ & $<0.001$ \\
\hline
\end{tabular}

Qualitative data presented as frequencies and percentages - $\mathrm{n}(\%)$; quantitative data presented as means with its standard deviations - M \pm SD. MAG,

middle-aged group; CG, control group. 
A comparative analysis of the frequency of concomitant somatic pathology in different age groups in patients with POAG and the control group is presented in Table 2.

When comparing the frequency of concomitant pathology in patients with POAG by age groups, a decreasing tendency in the share of people with one and two concomitant pathologies from middle age to old age and very old age was detected. The share of patients with three concomitant pathologies increased 2.22 times in the age group of 60-74 years and 2.87 times in the group of over 75 years, compared with the age group of $45-59$ years $(p<0.001)$. The share of patients with four concomitant pathologies was 4.3 times and 5.42 times higher in the old age group and in the very old age group $(p<0.001)$, respectively, than the share of middleaged POAG patients with the same number of pathologies.

The share of people with POAG and five concomitant diseases increased 6.25 times in the group of 60-74 years old, 10.01 times in the group over 75 years old compared with the middle age group $(\mathrm{p}<0.001)$. Patients with POAG and six concomitant somatic diseases were found only in the age group of 75 years and older.

An increase in the comorbidity index with age was noted: 3.02 times in the old age group and 4.2 times in the very old age group, compared with the group of middle age patients $(p<0.001)$; while considered against the control group, it was higher 1.42 and 1.97 times, respectively $(p<0.001)$.

\section{Discussion}

The study established a difference in the prevalence of concomitant somatic pathology among various age groups. On the one hand, as the age of POAG patients increased, the number of patients with hypertension, ischemic heart disease, cerebrovascular accident, atherosclerosis, degenerative diseases of the nervous system, diabetes mellitus, diseases of the respiratory system, musculoskeletal system, and other pathologies (from middle-aged to old and very old patients) grew statistically. On the other hand, a significant decrease in the diagnosis of arterial hypotension, thyroid pathology, and gastrointestinal tract disorder was observed in very old patients with POAG.

Several authors noted the prevalence of cardiovascular pathologies, such as A.H., IHD, DEP, ATS, among concomitant somatic diseases, autonomic and endothelial dysfunction in patients with POAG $[2,3,7,8]$.

H.C. Lin et al., when comparing the prevalence of somatic diseases in groups of patients with POAG and without glaucoma, established the following prevalence of diseases: diabetes $30.2 \%$ versus $19.5 \%$, hypertension $50.5 \%$ versus $40.3 \%$, congestive heart failure $6.5 \%$ versus $5.0 \%$, hyperlipidemia $30.5 \%$ versus $19.3 \%$, and IHD $2.4 \%$ versus $1.9 \%[16]$.

Many studies demonstrated that changes in systemic and cerebral hemodynamics play a significant role in the ischemia progression in the tissues of the brain and eye, as well as glaucoma development and progression $[9,10]$. A connection between the POAG severity and a decrease in blood flow was found in the vessels of the brain and eye [17].

The endocrine system pathology has been noted as a significant risk factor for POAG development, along with cardiovascular diseases $[11,18]$. We revealed an increase in the share of diabetic patients and a decrease in the share of patients with thyroid pathology in the old age and very old age groups.
Our study identified a statistically significant increase in the comorbidity index with age when comparing the groups with each other and with the control group. Significant growth in the comorbidity index for somatic pathology in patients with POAG in different age groups was observed in the study by S.I. Makogon et al., who identified M. Charlson's comorbidity index values of 1.5 in the middle age group, 2.3 in the elderly group, and 3.4 in the very old age group [19]. Thus, the emergence of clinically associated conditions, manifested by an increase in the comorbidity index, is associated with POAG and is a natural manifestation of age-related changes.

\section{Conclusion}

In patients with POAG, the number of patients with hypertension, ischemic heart disease, cerebrovascular disorders, atherosclerosis, degenerative diseases of the nervous system, diabetes mellitus, respiratory diseases, musculoskeletal system disorders, and other pathologies increased significantly with age.

The comorbidity index in POAG patients exhibited an upward tendency with age: 3.02 times in the old age group and 4.2 times in the group of very old age people vs. the group of middle-aged patients $(p<0.001)$; and 1.42 and 1.97 times, respectively, vs. the control group $(p<0.001)$.

\section{Limitations}

The main limitation of our study is a relatively small sample size and the lack of a follow-up in POAG patients and the control group for some time. The somatic status of patients was assessed using anamnestic and documentary data, including the medical report by the therapist and other specialists within the last six months, as per medical documentation provided without using the laboratory and additional instrumental research methods to identify, confirm, or refute the established somatic pathology. This study focuses more on analyzing concomitant somatic diseases in POAG patients rather than examining some aspects of their mutual influences. However, the necessity to identify such interaction patterns in further studies is beyond any doubt.

\section{Conflict of Interest}

Conflict of interest is not stated.

\section{Ethical approval}

All procedures performed in studies involving human participants were in accordance with the ethical standards of the institutional research committee and with the 1964 Declaration of Helsinki and its later amendments or comparable ethical standards.

\section{References}

1. Egorov EA, Ed. National Guidelines for Glaucoma. 2019; 384 p. Russian. https://doi.org/10.33029/9704-5442-8-GLA-2020-1-384.

2. Yanagi $M$, Kawasaki R, Wang JJ, Wong TY, Crowston J, Kiuchi $Y$. Vascular risk factors in glaucoma: a review. Clin Exp Ophthalmol 2011; 39(3): 252-258. https://doi.org/10.1111/j.1442-9071.2010.02455.x.

3. Yancik R, Ershler W, Satariano W, Hazzard W, Cohen HJ, Ferrucci L. Report of the national institute on an aging task force on comorbidity. J Gerontol A Biol Sci Med Sci 2007; 62(3): 275-280. https://doi.org/10.1093/gerona/62.3.275.

4. Charlson ME, Pompei P, Ales KL, Mackenzie CR. A new method of classifying prognostic comorbidity in longitudinal studies: development 
and validation. J Chronic Dis 1987; 40(5): 373-383. https://doi.org/10.1016/0021-9681(87)90171-8.

5. Sobyanin NA, Agafonova TY, Gavrilova TV. The importance of comorbidity of primary open-angle glaucoma and cardiovascular pathology for the choice of systemic drug therapy. Glaucoma news 2017; (1(41)): 82-83. Russian. https://elibrary.ru/item.asp?id=27432825.

6. Makogon SI, Makogon AS. The study of comorbidity in patients with primary open-angle glaucoma in different age groups. National Journal glaucoma 2017; 16(1): 7-15. https://www.elibrary.ru/item.asp?id=28840982.

7. Alexeev VN, Zaporozhetc LA, Al-Maisam R. Primary glaucoma in patients with various somatic diseases: main features of monitoring and disease course. RMJ. Clinical ophthalmology. 2016; 16(2): 79-82. Russian. https://doi.org/10.21689/2311-7729-2016-16-2-79-82.

8. Lin HC, Chien CW, Hu CC, Ho JD. Comparison of comorbid conditions between open-angle glaucoma patients and a control cohort: a casecontrol study. Ophthalmology 2010; 117(11): 2088-2095. https://doi.org/10.1016/j.ophtha.2010.03.003.

9. Kunin VD, Redid A.A. The influence of blood filling of the cerebral vessels on the ocular hemodynamics and the course of glaucoma. National Journal glaucoma 2014; 13(2): 40-49. Russian. https://www.elibrary.ru/item.asp?id=21977529.

10. Hayreh SS. Pathogenesis of glaucomatous optic neuropathy. In: Ocular Blood Flow and Glaucomatous Optic Neuropathy. Berlin, Heidelberg: Springer. 2009: 75-78. https://doi.org/10.1007/978-3-540-69443-4_8.

11. Zeng J, Liu H, Liu X, Ding C. The relationship between Helicobacter pylori infection and open-angle glaucoma: A Meta-Analysis. Invest Ophthalmol Vis Sci 2015; 56(9): 5238-5245. https://doi.org/10.1167/iovs.15-17059.

12. Berdahl JP, Fleishman D, Zaydlarova J, Stinnett S, Allingham RR, Fautsch MP. Body mass index has a linear relationship with cerebrospinal fluid pressure. Invest Ophthalmol Vis Sci 2012; 53(3): 1422-1427. https://doi.org/10.1167/iovs.11-8220.

13. Liu W, Ling J, Chen Y, Wu Y, Lu P. The association between adiposity and the risk of glaucoma: a meta-analysis. J Ophthalmol 2017; 2017: 9787450. https://doi.org/10.1155/2017/9787450.

14. Egorov EA, Erichev VP, Onishchenko AL, Petrov SYu, Kuroyedov AV, Antonov AA, et al. Systemic risk factors for developing of primary open-angle glaucoma. RMJ. Clinical ophthalmology 2018; 18(3): 140145. Russian. https://doi.org/10.21689/2311-7729-2018-18-3-140145.

15. Kim M, Kim TW, Park KH, Kim JM. Risk factors for primary open-angle glaucoma in South Korea: the Namil study. Jpn J Ophthalmol 2012; 56(4): 324-329. https://doi.org/10.1007/s10384-012-0153-4.

16. Kakigi $C$, Kasuga $T$, Wang SY, Singh K, Hiratsuka $Y$, Murakami A, et al. hypothyroidism and glaucoma in the United States. PLoS One 2015; 10(7): e0133688. https://doi.org/10.1371/journal.pone.0133688.

17. Shim SH, Kim JM, Woo HY, Shin KU, Koh JW, Park KH. Association between platelet function and disc hemorrhage in patients with normal-tension glaucoma: a prospective cross-sectional study. Am J Ophthalmol 2015; 160(6): 1191-1199.e1. https://doi.org/10.1016/j.ajo.2015.09.006.

18. Yang XJ, Ge J, Zhuo YH. Role of mitochondria in the pathogenesis and treatment of glaucoma. Chin Med J (Engl) 2013; 126(22): 4358-4365. https://pubmed.ncbi.nlm.nih.gov/24238529.

19. Osborne NN, Núñez-Álvarez C, Joglar B, Del Olmo-Aguado S. Glaucoma: focus on mito-chondria in relation to pathogenesis and neuroprotection. Eur J Pharmacol 2016; 787: 127-133. https://doi.org/10.1016/j.ejphar.2016.04.032.

20. Moon JY, Kim HJ, Park YH, Park TK, Park EC, Kim CY, et al. Association between open-angle glaucoma and the risks of Alzheimer's and Parkinson's diseases in South Korea: a 10-year nationwide cohort study. Sci Rep 2018; 8(1): 11161. https://doi.org/10.1038/s41598-01829557-6.

\section{Authors:}

Aigul Sh. Zagidullina - MD, Associate Professor, Department of Ophthalmology, Bashkir Medical State University, Ufa, Russia. https://orcid.org/0000-0003-4576-3709.

Bulat M. Aznabaev - PhD, Professor, Chair of the Department of Ophthalmology, Bashkir Medical State University, Ufa, Russia. https://orcid.org/0000-0003-1796-8248. 